\title{
The Lower Limb Kinematics Analyze of Junior School Freshmen (Girls)
}

\author{
Jiabin $\mathrm{Ma}^{1 *}$ and Zhouzhou $\mathrm{Mao}^{2}$ \\ ${ }^{1}$ Ningbo Shi Haishu Qu Tianxingeng Zhongxue, China \\ ${ }^{2}$ Li Huili Hospital, China
}

Submission: March 23, 2018; Published: April 13, 2018

*Corresponding author:Jiabin Ma, Ningbo Shi Haishu Qu Tianxingeng Zhongxue, Ningbo, Zhejiang, China, Email: jiabin8308@126.com

\begin{abstract}
This study is aimed to find out the lower limb (hip, knee, and ankle) kinematics specialty of junior school girl students, and compare it with the parameter of adults to find out the characteristics of the lower limb kinematics in Juvenile stage, and more desired to explore the law about it to provide the basis for physical training in juvenile stage. Fifteen junior school girl students age at 13 to 14 years old participated in this study. The Vicon kinematics analysis system (Oxford, Metrics, Ltd., Oxford, UK) with a shooting frequency of $200 \mathrm{~Hz}$ was used to collect the threedimensional kinematics of the hip, knee and ankle joint.
\end{abstract}

Keywords: Lower limb; Kinematics; Junior school; Freshmen

\section{Introduction}

Junior middle school is a sensitivity and critical period for junior student's body development and Joint growth. Mastering the conditions of students' body posture and muscle development is helpful to guide students to form the correct walking posture, plan individual training for students, explore scientific and feasible training methods, form the correct body posture for students, enhance the strength and condition, and develop students' interest in sports activities.

In reality, there were some phenomena of faulty running posture and movement not in place, including splayed feet, thighs not lift or less lift, sitting running posture, Clamping arms during running and so on, which seriously affected the improvement of students' grades and the formation of correct running posture. For a long time, it may cause changes in body shape, even damage to the body and affect the posture. The energy consumption of an abnormal gait pattern is more, which can result in poor endurance, and increase stress on joints causing problems with pain in adulthood [1]. Deviations in the movement pattern can be a primary disorder, or a compensation for problems in adjacent joints [2]. It is of great value to normalize the gait pattern in order to reduce energy consumption, increase speed and prevent future problems with pain [3]. Therefore, this study hopes to use biomechanics methods to quantitative analyses the junior girl students' body kinematics parameters during walking. And this study compared the students and adult women in kinematics parameters to find out the faculties and defects between them, lower limb kinematics in junior middle school girl students and the difference of adult women on limb kinematics. Than according to the results, planning and implementing the scientific and feasible lower extremity strength and postural training programs.

\section{Methods}

\section{Participants}

This study selected 15 healthy junior high school girl students as participants involved in the study; all participants were come from Tianxingeng middle school, and had no leg or foot disease in the past half year (Table 1).

Table 1: The basic situation of the subjects.

\begin{tabular}{|c|c|c|c|c|}
\hline Group & Age (Y) & High (cm) & Weight (k) & $\begin{array}{c}\text { Exercise } \\
\text { Time } \\
\text { (h/D) }\end{array}$ \\
\hline $\begin{array}{c}\text { Girl } \\
\text { students } \\
(15)\end{array}$ & $13.2 \pm 1.1$ & $162.8 \pm 2.2$ & $45.9 \pm 3.6$ & Within 0.5 \\
\hline
\end{tabular}

\section{Design}

Gait biomechanical parameters was the mainly indexes of this study, all participants were naked feet and divided into 15 healthy junior high school girl students. Before the experiment, participants were asked to walk barefoot for 10 minutes in order to adapt to the effects of barefoot walking. Test data was based on the participants' right lower limbs. This study was conducted 
in the Ningbo University sports biomechanics laboratory, threedimensional kinematics analysis used 8 infrared camera of Vicon motion analysis system (Oxford Metrics, Ltd., Oxford, UK) to capture the kinematics, and the shooting frequency was $200 \mathrm{~Hz}$. The angle, midpoint, and axis of rotation were defined by the standard position of the mark point [4]. Participants were asked to wear tight shorts, 16 reflection (diameter $14 \mathrm{~mm}$ ) were pasted around the outside of lower limb: Anterior superior spine, midthigh, knee joint, mid-calf, femoral epicondyle, ankle, the second metatarsus head and calcaneus. The signs of the heel and toe part were posted in the anatomical position of the shoes. The gait cycle is divided into the initial support stage $(0-10 \%)$, the middle support stage $(10-30 \%)$, the end support stage (30$50 \%)$, the push-off period (50-60\%) and swing phase $(60 \%-$ $100 \%)$. Before the test, the participants could choose their best controlled speed to walk along the $12 \mathrm{~m}$ walkway. This study selected two step stable gait data of each test are analyzed, in order to reduce the experimental error. The two most stable gait data of each test were selected for analysis in this study to reduce the experimental error.

\section{Statistical Analysis}

Indicators for statistical data analysis were joint range of motion (ROM) and three dimensional kinematic data of the right lower extremity including the angle peak of the hip, knee and ankle. SPSS 20.0 software (SPSS, Chicago, IL, US) was used for statistical analysis.

\section{Results and Analysis}

\section{Ankle Kinematics}

There was a significant difference between group with students and adult one in the angle of the ankle with dorsiflexion and plantarflexion, from the Figure 1, the angle of ankle with dorsiflexion of the group with students was smaller than the adult group, but the angle of the ankle with plantarflexion showed increasing trend.
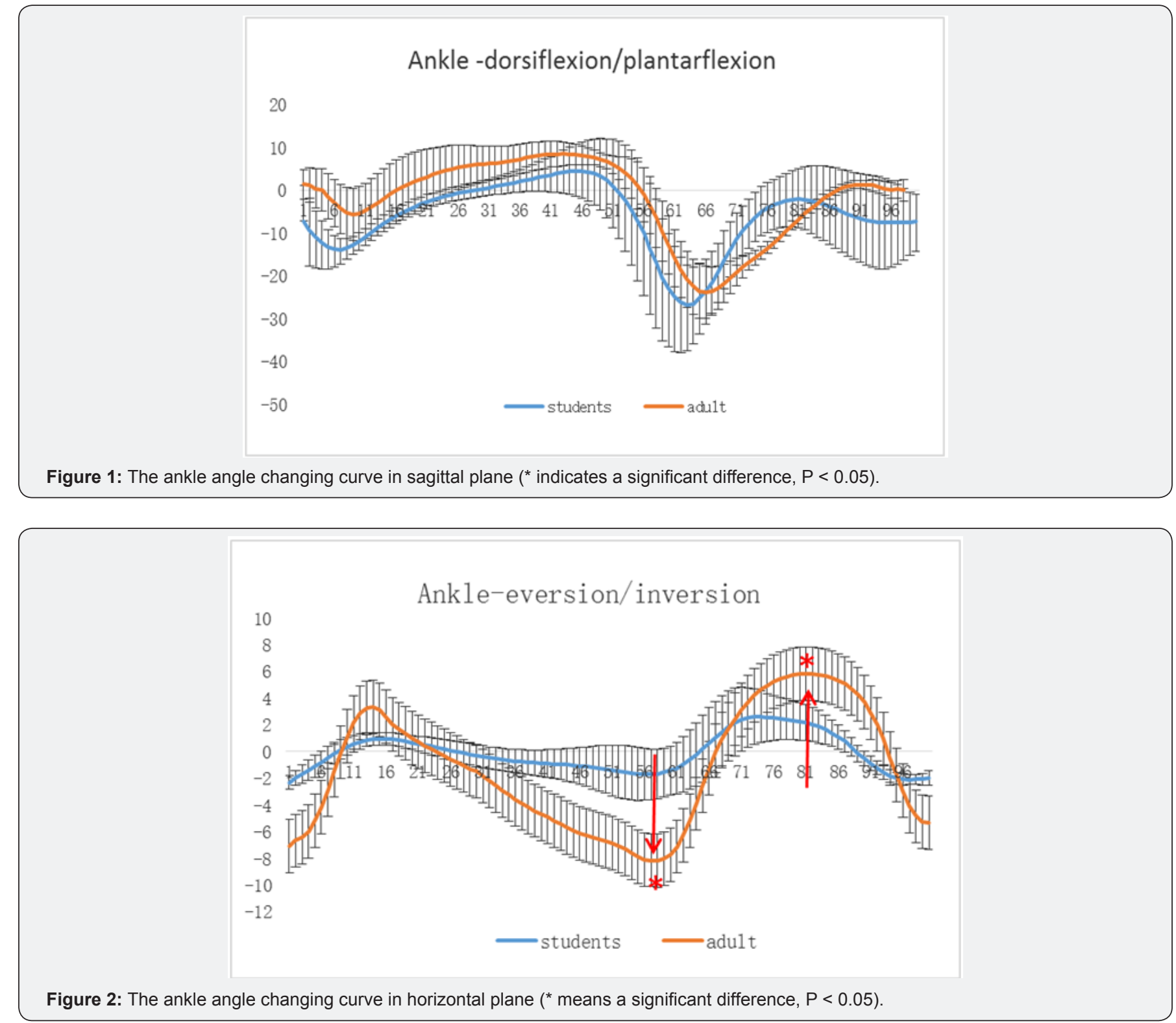
Compared the group with students and adult group in the ankle with eversion or inversion angle, this study discovered that participants with adult had bigger ankle eversion and invension trend, and the difference of ankle eversion peak between them was significantly different (Figure 2). But during the push-off period, adult group's angle of ankle with eversion was obviously higher than students group.
The ankle internal rotation range of students group show obviously lower trend than adult group. Especially during the push-off period, the ankle internal rotation of adult group appeared a significant increase trend, while the students group kept relatively smooth (Figure 3). In the swing phase, the external rotation range shown a clearly increasing trend while the external of students group was relatively smaller, and there was a significant difference between them.

\section{Ankle- internal/external rotation}

40

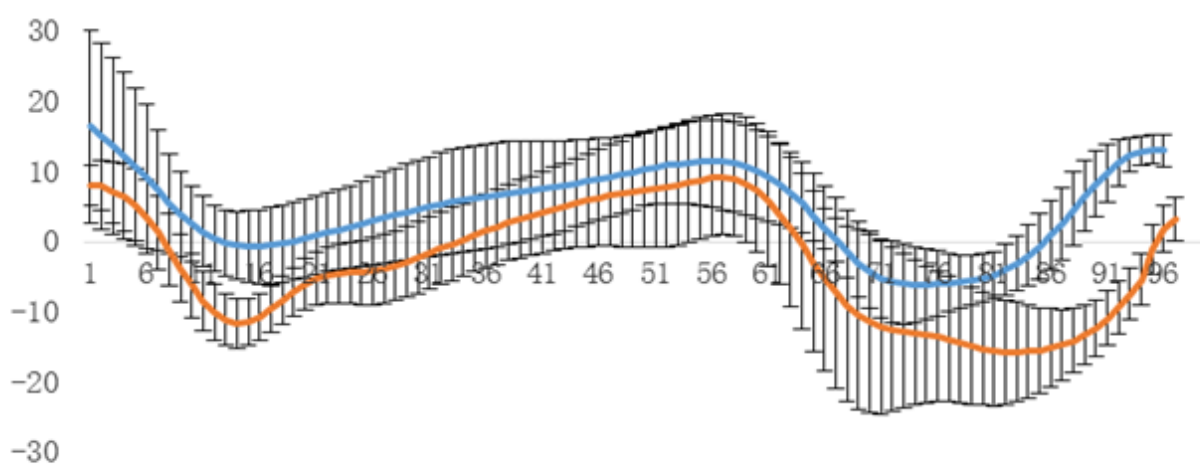

students

Figure 3: The ankle angle changing curve in coronal section (* means a significant difference, $\mathrm{P}<0.05$ ).

\section{Knee Kinematics}

There was no significant difference between participants with students and adult group in the angle of knee flexion and extension (Figure 4). The results compared with the data of the young population shown that the maximum angle of knee flexion was considerably difference from the adults' during the early fall and swing phase. This declared that the junior middle school stage girls' knee angle changing trend had few difference with the adult during the walking, but the flexion range of the knee angle had not reach the demand of adults which might due to the strength of the knee and the articular ligament were still not fully developed so couldn't bear greater flexion range demands. It also points out the direction for the middle school sports teaching that should strengthen the leg strength training of the students, especially the strength exercise near the knee joint muscle.

\section{$\mathrm{Knee}^{-}$flexion/extension}

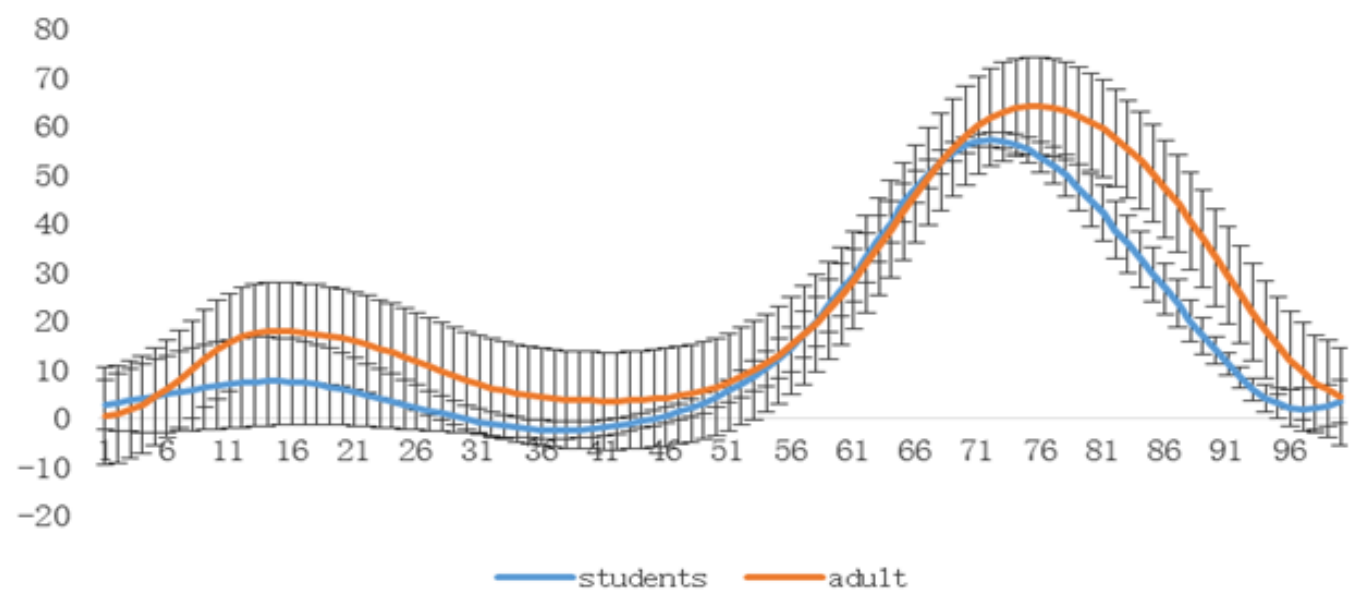

Figure 4: The knee angle changing curve in vertical plane $\left({ }^{*}\right.$ means a significant difference, $\left.P<0.05\right)$. 


\section{Hip Kinematics}

The angle pf the hip flexion of the training group with students was greater than adult group, found by comparing the angle of the hip flexion and extension, but showed no significant difference (Figure 5). This might result from the muscles strength of the hip and legs of the adult group has gained more fully trained. The thigh contracted more fully causing the much bigger extension angle of the hip in the swing phase. In final support stage participants with students has no significant difference of peak of the hip extension, compared with the data of the hip angle of adult female [5-8].

\section{Hip-flexion/extension}

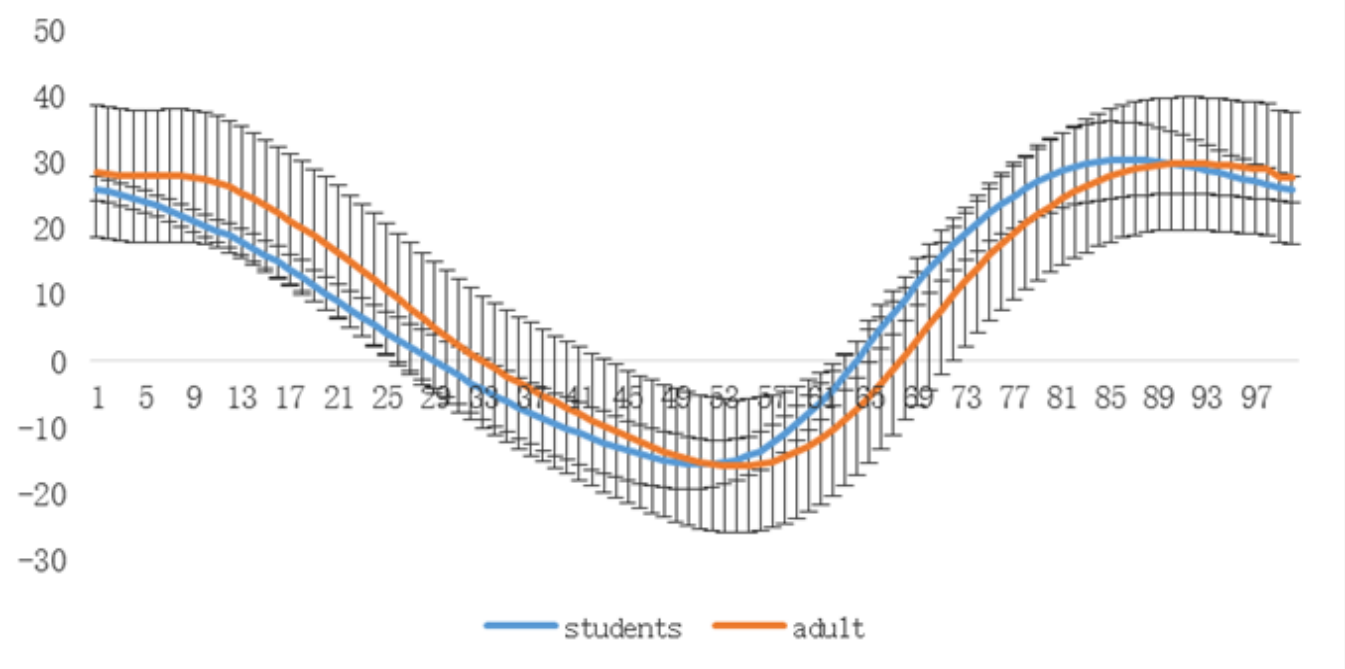

Figure 5: The hip angle changing curve in vertical plane $\left({ }^{*}\right.$ means a significant difference, $\left.P<0.05\right)$.

\section{Conclusion}

Junior students are in a critical period of body development and growth, their lower extremity kinematics has differences with adults. Exercise is beneficial to the growth and development of the lower extremity joint and muscles to making the waking posture much reasonable and avoids the possible injury effectively. Students with exercise habits shown some advantages in step and pace than students without exercise habits, the muscle forces of lower extremities has been developed by increasing the step size and reducing the pace improved the gait stability. All proved that exercise habits have positive effects on the stability of joint, such as the joint force can be better controlled, improving the walking stability, and avoiding injury.

But the effects of lack of physical exercise and sports on health have a lag decided by the characteristics of the body adapt to stimuli. Therefore, the cultivating the students have sports hobbies and good exercise habits even interested in physical exercise to participate in sports activities have significance means to improve the physical quality of the whole nation.

\section{References}

1. C Andersson, E Mattsson (2001) Adults with cerebral palsy: A survey describing problems, needs, and resources, with special emphasis on locomotion. Dev Med Child Neurol 43(2): 76-82.
2. JR Gage, TF Novacheck (2001) An update on the treatment of gait problems in cerebral palsy. J Pediatric Orthop 10(4): 265-274.

3. Meta N Eek, Roland Zügner, Ingibjörg Stefansdottir, Roy Tranberg (2017) Kinematic gait pattern in children with cerebral palsy and leg length discrepancy: Effects of an extra sole. Gait \& Posture 55: 150156.

4. Kadaba MP, Ramakrishnan HK, Wootten ME (1990) Measurement of lower extremity kinematics during level walking. Journal of Orthopaedic Research 8(3): 383-392.

5. Ma Jiabin (2014) Studying about the function of shoes with unstable structure. Master's degree thesis of Ningbo University, China.

6. Yu Ting, Wang Shaobing, Yu Taiying, Qin Changkun (2015) The effects of physical exercise on the characteristic of College Students' gait. Human movement science 5(18): 7-8.

7. Pedro Ángel Latorre Román, Fernando Redondo Balboa, Felipe García Pinillos (2017) Foot strike pattern in children during shod-unshod running. Gait and Posture 58: 220-222.

8. BJ Krabak, B Snitily, CJE Milani (2016) Understanding and Treating Running Injuries in the Youth Athlete. Curr Phys Med Rehabil Reports 4(2): 161-169. 
Your next submission with Juniper Publishers will reach you the below assets

- Quality Editorial service

- Swift Peer Review

- Reprints availability

- E-prints Service

- Manuscript Podcast for convenient understanding

- Global attainment for your research

- Manuscript accessibility in different formats ( Pdf, E-pub, Full Text, Audio)

- Unceasing customer service

Track the below URL for one-step submission https://juniperpublishers.com/online-submission.php 